\title{
Analysis of apoptosis methods recently used in Cancer Research and Cell Death \& Disease publications
}

\author{
O Bucur ${ }^{1,2,5}$, AL Stancu ${ }^{1,3,5}$, R Khosravi-Far ${ }^{\star, 1}$, A Almasan ${ }^{\star, 4}$ \\ Cell Death and Disease (2012) 3, e263; doi:10.1038/cddis.2012.2; published online 2 February 2012
}

Over several decades, significant advances have been made in implementing several morphological and biochemical criteria to define and characterize apoptosis. In order to appropriately identify apoptosis in cellular cultures or in vivo (animal models), with the ultimate aim of discovering novel, useful, specific, and powerful pro-apoptotic antitumoral drugs, it is necessary to accurately validate apoptotic processes through morphological, biochemical, or immunological methods.

Often, apoptosis is detected and/or measured by only one method and the authors frequently use imprecise terminology, such as '\% apoptosis', '\% cell death', instead of defining the specific method used such as '\% cells with condensed chromatin', '\% cells TUNEL positive', ‘\% cells Annexin V positive' and others. ${ }^{1}$ The Nomenclature Committee on Cell Death (NCCD) recommends and encourages researchers to demonstrate that apoptosis or other forms of cell death take place using more than one assay, as an artifact removal feature, and to avoid the 'confusing and imprecise' nomenclature, such as '\% apoptosis', which 'should definitively be abandoned'. ' Moreover, the NCCD 'urges' all life science journals to join the Cell Death and Differentiation journal in adopting these recommendations. ${ }^{1}$

In order to determine the level of compliance with these recommendations, we analyzed 110 Cancer Research articles that detect/measure apoptosis, published between August 15, 2010 and February 15, 2011, and 120 similar research articles published in Cell Death \& Disease between January 1, 2010 and September 2011. In 21 of the Cancer Research and 15 of the Cell Death \& Disease articles, apoptosis was determined by the authors for different treatments or in different settings using a different combination of apoptosis techniques each time, thus leading the total number of apoptotic determinations (entries) to 137 (Cancer Research) and 136 (Cell Death \& Disease) (see Table 1 and Table 2). The results clearly show that in only 60 of the 137 entries (43.8\%) for Cancer Research and 96 of the 136 entries $(70.58 \%)$ for Cell Death \& Disease, the authors used at least two different methods for apoptosis detection. In addition, we determined that in 5 of the 137 (3.64\%) entries from Cancer Research and in 34 of the 136 (25\%) of the entries from Cell Death \& Disease the authors use at least three methods for apoptosis detection (Figure 1). Moreover, it is important to emphasize that most, if not all of the apoptosis techniques used to detect apoptosis as single methods may, as shown by some reports, also detect necrosis or other cellular processes. As an example, DNA fragmentation measured by terminal deoxynucleotidyl transferase (TdT)-mediated dUTP nick end labeling (TUNEL) (26 of 137 from Cancer Research; 26 of 136 from Cell Death \& Disease) or subG1 DNA content (30 of 137 from Cancer Research; 18 of 136 from Cell Death \& Disease) or Annexin V alone, without PI/7AAD (16 of 137 from Cancer Research; 7 of 136 from Cell Death \& Disease) and other assays can also detect necrosis. ${ }^{1-6}$ In addition, caspases can be activated during cellular processes other than apoptosis. ${ }^{1}$ Thus, more than one method for apoptosis detection should be used.

In order to investigate the proper use of the specific name for each method used, we analyzed the same entries described above. Our analysis shows similar results for the two journals. While for Cell Death \& Disease, 83 from 136 entries $(61.02 \%)$ use the name of the specific method used for apoptosis detection, among the 137 entries from Cancer Research, $87(63.5 \%)$ use the name of the specific method used (Figure 1). These results certainly leave space for improvement.

In conclusion, these results clearly suggest the need for improvements and of adequate guidelines for authors, reviewers, and editors regarding the apoptosis (in particular) and cell death (in general) detection, and quantification methods.

\footnotetext{
${ }^{1}$ Department of Pathology, Harvard Medical School and Beth Israel Deaconess Medical Center, Boston, MA, USA; ${ }^{2}$ Department of Molecular and Cell Biology, Institute of Biochemistry of the Romanian Academy, Bucharest, Romania; ${ }^{3}$ Carol Davila University of Medicine and Pharmacy, Bucharest, Romania; ${ }^{4}$ Department of Cancer Biology, Lerner Research Institute, Cleveland Clinic Foundation, Cleveland, OH, USA

${ }^{*}$ Corresponding authors: A Almasan, Department of Cancer Biology, Lerner Research Institute, Cleveland Clinic Foundation, 9500 Euclid Avenue, Cleveland, OH 44195, USA. Tel: + 1216444 9970; Fax: + 1216445 6269; E-mail: almasaa@ccf.org or R Khosravi-Far, Department of Pathology, Harvard Medical School and Beth Israel Deaconess Medical Center, 330 Brookline Avenue, Boston, MA 02215, USA. Tel: +1 617667 8526; Fax: +1 1617667 8812; E-mail: rkhosrav@ bidmc.harvard.edu

${ }^{5}$ These authors contributed equally to this work.
} 
Table 1 Evaluation of the Cancer Research experimental articles measuring apoptosis, published between August 15, 2010 and February $15,2011^{7-116}$

\begin{tabular}{|c|c|c|}
\hline 2009 NCCD recommendations & $\begin{array}{c}\% \text { from } 137 \\
\text { entries }\end{array}$ & Details/comments \\
\hline $\begin{array}{l}\text { Use the specific name of the apoptosis } \\
\text { method }(A) \\
\text { At least two methods for apoptosis } \\
\text { detection (B) }\end{array}$ & $\begin{array}{l}87 / 137=63.5 \% \\
60 / 137=43.8 \%\end{array}$ & $\begin{array}{l}36.5 \% \text { of all entries use expressions such as '\% apoptosis', '\% apoptotic cells', 'relative } \\
\text { apoptotic cells (fold change)', '\% death' and others, instead of indicating the specific method } \\
\text { Amongst } 77 / 137 \text { entries only one method is used: } 26 / 79 \text {-caspase cleavage/activation; } 3 / 79 \\
\text { only PARP cleavage; } 31 / 79 \text { DNA fragmentation/nuclear condensation; } 15 / 79 \text { TUNEL; } 1 / 79 \\
\text { TUNEL and ELISA; } 8 / 79 \text { subG1; } 2 / 79 \text { subG1 and ELISA; } 2 / 79 \text { subG1 and Hoechst; } 1 / 79 \\
\text { Hoechst; } 1 / 79 \text { Yo-Pro-1; } 9 / 79 \text { Annexin } \mathrm{V} \text { only, } 6 / 79 \text { Annexin } V \text { with } \mathrm{PI} / 7-\mathrm{AAD}, 1 / 79 \text { Citokeratin- } \\
18 \text { cleavage; } 1 / 79 \text { only Trypan blue exclusion and clonogenic assay; } 1 / 79 \text { only Calcein/ethidium } \\
\text { bromide staining. }\end{array}$ \\
\hline
\end{tabular}

Methods

Caspase activation/Caspase cleavage/

84/137 $=61.13 \% \quad$ 11/84 PARP cleavage only (without examining caspase activation)

PARP cleavage (1)

DNA fragmentation/nuclear

condensation (2)

Plasma membrane integrity/PS

exposure (3)

Activation of pro-apoptotic Bcl-2 family

members (4)

Mitochondrial potential/integrity, release

of pro-apoptotic factors (5)

ROS detection (6)

Other apoptotic features (blebbing/

floating cells etc) (7)

No. of entries using methods (1) and (2)

No. of entries using methods (1) and (3)

No. of entries using methods (2) and (3)

$66 / 137=48.17 \%$

30/66 subG1; 26/66 TUNEL; 7/66 ELISA-nucleosomal fragmentation/release; 9/66 Hoechst

33342/33258, DAPI, Yo-Pro-1 (condensed/ fragmented chromatin)

(16/42 of entries examine Annexin V positive cells only (not combined with PI/7AAD)

$1 / 137=0.7 \%$

$6 / 137=4.38 \%$

$1 / 6$ shows Bax accumulation in the mitochondria; other $5 / 137$ show only total levels of the pro/ anti-apoptotic members

3/6 measure MMP and cyt c release together; 1/6 detect MMP only; 2/6 detect the Apo2.7 early

apoptotic marker

$2 / 137=1.45 \% \quad 2 / 2$ counting of floating cells (not specific for apoptosis)

$32 / 137=21.89 \% \quad 15 / 30$ subG1+activation/cleavage of caspases/ PARP (method 1 ); $10 / 30$ TUNEL+method 1

$24 / 137=17.51 \% \quad 21 / 24$ Annexin V/PI(or 7-AAD)+method $1 ; 3 / 87$ Annexin $\mathrm{V}$ only (without PI/7-AAD)+method

$6 / 137=4.38 \% \quad 3 / 6$ - subG1+Annexin V/with or without PI (or 7-AAD); 3/6 Hoechst/DAPI+Annexin V with/

$3 / 6$ - subG1+Annexin
without PI or 7-AAD)

$5 / 137=3.65 \% \quad$ Combinations of methods used: $1+2+3 ; 1+3+5 ; 1+3+6 ; 2+4+5+6 ; 1+2+5+7$

No. of entries using at least three of the considered methods

Abbreviations: AAD, 7-amino-actinomycin D; Cyt $c$, cytochrome $c$; DAPI, 4, 6-diamidino-2-phenylindole; DCFDA, dichlorofluorescin diacetate; MMP, mitochondrial membrane potential; PARP, poly(ADP ribose) polymerase 1; PI, propidium iodide; PS, phosphatidylserine; ROS, reactive oxygen species; TUNEL, terminal deoxynucleotidyl transferase (TdT)-mediated dUTP nick end labeling. Note: A higher number of articles were published in Cancer Research between August 15, 2010 and February 15, 2011; however, they measured other non-apoptotic cellular processes: non-apoptotic cell death and signaling, mitotic catastrophe, autophagy, proliferation, metastasis, and others ${ }^{117-162}$

Table 2 Evaluation of the Cell Death \& Disease experimental articles measuring apoptosis, published between January 1, 2010 and September, $2011^{163-282}$

\begin{tabular}{|c|c|c|}
\hline 2009 NCCD recommendations & $\begin{array}{c}\% \text { from } 136 \\
\text { entries }\end{array}$ & Details/comments \\
\hline $\begin{array}{l}\text { Use the specific name of the } \\
\text { apoptotic method }(A)\end{array}$ & $83 / 136=61.03 \%$ & $\begin{array}{l}38.97 \% \text { of all entries use expressions such as '\% apoptosis', '\% apoptotic cells', 'relative apoptotic cells } \\
\text { (fold change)', '\% death' and others, instead of mentioning the specific method }\end{array}$ \\
\hline $\begin{array}{l}\text { At least two methods for apoptosis } \\
\text { detection (B) }\end{array}$ & $96 / 136=70.58 \%$ & $\begin{array}{l}\text { 40/136 entries use only one method for apoptosis detection: } 14 / 40 \text { caspases cleavage/activation; } 1 / 40 \\
\text { only PARP cleavage detection; } 12 / 40 \text { DNA fragmentation/nuclear condensation (5/40 TUNEL; } 3 / 40 \\
\text { subG1; } 3 / 40 \text { Hoechst; } 1 / 40 \text { nucleosomal fragmentation/release); } 10 / 40 \text { AnnexinV+/-PI/7AAD or } \\
\text { To-Pro-3; } 2 / 40-M M P ; 1 / 40 \text { PI only }\end{array}$ \\
\hline
\end{tabular}

Methods

Caspase activation/caspase cleavage/PARP cleavage (1)

DNA fragmentation/nuclear

condensation (2)

Plasma membrane integrity/PS exposure (3)

Activation of pro-apoptotic Bcl-2

family members (4)

Mitochondrial potential/integrity

release of pro-apoptotic

factors (5)

ROS detection (6)

Other apoptotic features

(blebbing/apoptotic bodies) (7)

No. of entries using methods (1) and (2)

No. of entries using methods (1)

and (3)

No. of entries using methods (2)

and (3)

No. of entries using at least three of the considered methods
94/136 $=69.11 \% \quad$ 7/94-PARP cleavage detection only (without examining caspase activation/cleavage); 5/94 zVAD only (without caspase activation/cleavage evaluation)

$71 / 136=52.20 \% \quad$ 26/71 TUNEL; 18/71 subG1; 15/71 Hoechst, 7/71 nucleosomal fragmentation/release, 4/71 DNA ladder, 4/71 nuclear condensation/fragmentation (EM); 3/71 Acridine orange, 2/71 DAPI; 3/71 unspecified method (DNA fragmentation/condensation)

$57 / 136=41.91 \% \quad 52 / 57$ Annexin V+/-PI or 7AAD (7/57 use Annexin V only); 2/57 PI/Yo-Pro-1; 2/57 Annexin V/To-Pro-3;

7/7 measure Bax, Bak, or Bid activity, localization (Bax and Bak) or cleavage (Bid); other 14/137 entries determine only their total levels

$36 / 136=26.47 \% \quad 21 / 36$ Cyt c release from mitochondria; $19 / 36$ MMP; $4 / 36$ measure both Cyt c release and MMP; $3 / 36$ measure both Cyt $\mathrm{c}$ and Smac release

$14 / 136=10.29 \% \quad$ DFCDA and DHE measurements of ROS

$5 / 136=3.67 \% \quad 3 / 5$ cell blebbing; $2 / 5$ apoptotic bodies

45/136 $=33.08 \% \quad$ 19/45 TUNEL+activation/cleavage of caspases/ PARP (method 1); 10/45 subG1+method 1; 9/45

$32 / 136=23.52 \% \quad 28 / 32$ AnnexinV+PI, 7-AAD or To-Pro-3+method $1 ; 3 / 87$ Annexin V only (without PI/7-AAD)+method 1 . 1/32 PI/Yo-Pro-1+method 1 or To-Pro-3+method 1, 3/87 Annexin V only (without PI/7-AAD)+methc $19 / 136=13.97 \% \quad 7 / 19$ subG1+Annexin V with/without PI/7-AAD; 6/87 TUNEL+Annexin V with/without PI /7-AAD

$34 / 136=25 \% \quad$ Combinations of methods used: $5 / 34(1+2+3+5 ; 1+2+5 ; 1+3+5) ; 3 / 5(1+2+3 ; 1+4+5) ; 2 / 34(1+2+7 ;$ $1+3+6 ; 1+3+5+6) ; 1 / 6(1+2+6 ; 1+2+4 ; 1+5+6 ; 1+2+4+5 ; 1+3+5+6 ; 1+3+4+5 ; 1+2+4+5+6+7)$

Abbreviations: AAD, 7-amino-actinomycin D; Cyt $c$, cytochrome $c$; DCFDA, dichlorofluorescin diacetate; DHE, dihydroethidium; EM, electron microscopy; MMP, mitochondrial membrane potential; PARP, poly(ADP ribose) polymerase 1; PI, propidium iodide; PS, phosphatidylserine; ROS, reactive oxygen species. Note: A higher number of articles were published in Cell Death \& Disease between January 1, 2010 and September, 2011 ; however, they measured other non-apoptotic cellular processes: non-apoptotic cell death and cell signaling, mitotic catastrophe, autophagy, proliferation, metastasis, and others ${ }^{283-317}$ 
a

$\square$ Entries using general terms
such as "percent apoptosis"
$\square$ Entries using the specific name
of the method

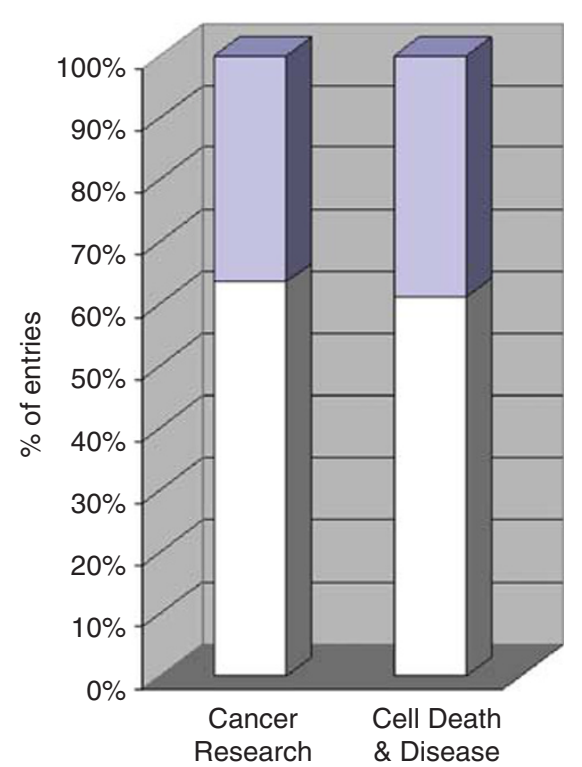

b
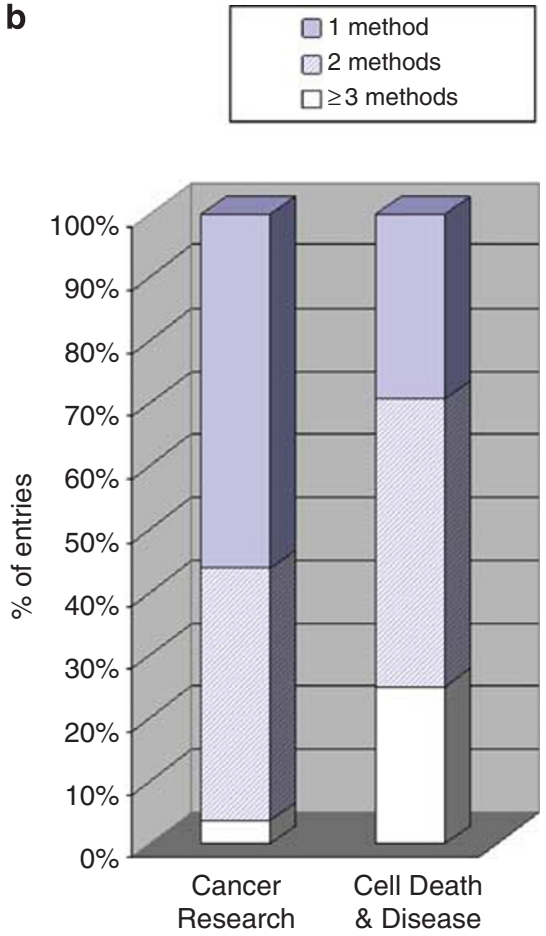

Figure 1 Evaluation of the Cancer Research and Cell Death \& Disease articles. (a) Percentage of entries using the specific name of the apoptosis method used (87 of $137=63.5 \%$ for Cancer Research; 83 of $136=61.03 \%$ for Cell Death \& Disease), instead of using the general terms such as '\% apoptosis'. (b) Percentage of entries using one, two ( 55 of $137=40.14 \%$ for Cancer Research; 62 of $136=45.58 \%$ for Cell Death \& Disease), or at least three methods ( 5 of $137=3.65 \%$ for Cancer Research; 34 of $136=25 \%$ for Cell Death \& Disease) for apoptosis detection/quantification

\section{Conflict of Interest}

The authors declare no conflict of interest.

Acknowledgements. $O B$ received a fellowship from the Lady TATA Memorial Trust, London, UK. This work was also supported by the National Institutes of Health grants CA127264 (to AA), CA105306, CA131664, and HL080192 (to RK).

1. Kroemer G et al. Cell Death Differ 2009; 16: 3-11.

2. Galluzzi L et al. Cell Death Differ 2012; 19: 107-120.

3. Grasl-Kraipp B et al. Hepatology 1995; 21: 1465-1146.

4. Jaeschhke H, Lemasters JJ. Gastroenterology 2003; 125: 1246-1257.

5. Qian L et al. Pathol Int 1995; 45: 207-214.

6. Vermes I et al. J Immunol Methods 1995; 184: 39-51.

7. Albesiano $\mathrm{E}$ et al. Cancer Res 2010; 70: 6467-6476.

8. Cai D et al. Cancer Res 2010; 70: 6477-6485.

9. Leung TH, Ngan HY. Cancer Res 2010; 70: 6486-6496.

10. Cheng $Y$ et al. Cancer Res 2010; 70: 6516-6526.

11. Xu J et al. Cancer Res 2010; 70: 6566-6576.

12. Landriscina $\mathrm{M}$ et al. Cancer Res 2010; 70: 6577-6586.

13. Chen R et al. Cancer Res 2010; 70: 6587-6597.

14. Shao Y, Aplin AE. Cancer Res 2010; 70: 6670-6681.

15. Rizvi $S$ et al. Cancer Res 2010; 70: 6787-6796.

16. Halilovic E et al. Cancer Res 2010; 70: 6804-6814.

17. Lee SO et al. Cancer Res 2010; 70: 6824-6836.

18. Hartley JA et al. Cancer Res 2010; 70: 6849-6858.

19. Brill E et al. Cancer Res 2010; 70: 6891-6901.

20. Sinnberg T et al. Cancer Res 2010; 70: 6999-7009.

21. Caruso JA, Hunt KK, Keyomarsi K. Cancer Res 2010; 70: 7125-7136.

22. Ibrahim N et al. Cancer Res 2010; 70: 7155-7165

23. Zhang $X$ et al. Cancer Res 2010; 70: 7176-7186.

24. Peterson QP et al. Cancer Res 2010; 70: 7232-7241.

25. Jiang J et al. Cancer Res 2010; 70: 7242-7252.

26. Mologni L et al. Cancer Res 2010; 70: 7253-7263.

27. Seo JH et al. Cancer Res 2010; 70: 7325-7335.

28. Hofbauer SW et al. Cancer Res 2010; 70: 7336-7344.

29. Geng D et al. Cancer Res 2010; 70: 7442-7454.
30. Herrmann A et al. Cancer Res 2010; 70: 7455-7464. 31. Doedens AL et al. Cancer Res 2010; 70: 7465-7475. 32. Buggins AG et al. Cancer Res 2010; 70: 7523-7533. 33. Kumar $\mathrm{M}$ et al. Cancer Res 2010; 70: 7553-7561. 34. Rossi EA et al. Cancer Res 2010; 70: 7600-7609. 35. Odri GA et al. Cancer Res 2010; 70: 7610-7619. 36. Cheng $X$ et al. Cancer Res 2010; 70: 7684-7689. 37. Yang PM et al. Cancer Res 2010; 70: 7699-7709. 38. Jiang $\mathrm{H}$ et al. Cancer Res 2010; 70: 7882-7893. 39. Yang D et al. Cancer Res 2010; 70: 7905-7917.

40. McKenzie JA et al. Cancer Res 2010; 70: 7927-7937.

41. Hastak K, Alli E, Ford JM. Cancer Res 2010; 70: 7970-7980.

42. Kohmo S et al. Cancer Res 2010; 70: 8025-8035.

43. Elyakim E et al. Cancer Res 2010; 70: 8077-8087.

44. Dong $Y$ et al. Cancer Res 2010; 70: 8088-8096.

45. Chiarini $F$ et al. Cancer Res 2010; 70: 8097-8107.

46. Yang $\mathrm{CH}$ et al. Cancer Res 2010; 70: 8108-8116.

47. Cole AM et al. Cancer Res 2010; 70: 8149-8158.

48. García-Barros M et al. Cancer Res 2010; 70: 8179-8186.

49. Omori E et al. Cancer Res 2010; 70: 8417-8425.

50. Hall CA et al. Cancer Res 2010; 70: 8517-8525.

51. Hong $L$ et al. Cancer Res 2010; 70: 8547-8557.

52. Jäämaa $S$ et al. Cancer Res 2010; 70: 8630-8641.

53. Pchejetski D et al. Cancer Res 2010; 70: 8651-8661.

54. Kunnumakkara AB et al. Cancer Res 2010; 70: 8695-8705.

55. Gopal YN et al. Cancer Res 2010; 70: 8736-8747.

56. Luoto KR et al. Cancer Res 2010; 70: 8748-8759.

57. Chock KL et al. Cancer Res 2010; 70: 8782-8791.

58. Chen $Y$ et al. Cancer Res 2010; 70: 8917-8926.

59. Ghosh JC et al. Cancer Res 2010; 70: 8988-8993.

60. Shibata T et al. Cancer Res 2010; 70: 9095-9105.

61. Wahdan-Alaswad RS et al. Cancer Res 2010; 70: 9106-9117.

62. de Souza Rocha Simonini $P$ et al. Cancer Res 2010; 70: 9175-9184.

63. Kapuria V et al. Cancer Res 2010; 70: 9265-9276.

64. Zhao $Y$ et al. Cancer Res 2010; 70: 9287-9297.

65. Ou DL et al. Cancer Res 2010; 70: 9309-9318.

66. Kuroda $S$ et al. Cancer Res 2010; 70: 9339-9348.

67. Hochgräfe F et al. Cancer Res 2010; 70: 9391-9401. 
68. Kalashnikova EV et al. Cancer Res 2010; 70: 9402-9412 69. Darsigny M et al. Cancer Res 2010; 70: 9423-9433. 70. Zhou X, Münger K. Cancer Res 2010; 70: 9434-9443. 71. Lin SL et al. Cancer Res 2010; 70: 9473-9482.

72. Gruenbacher $\mathrm{G}$ et al. Cancer Res 2010; 70: 9611-9620.

73. Fenouille $\mathrm{N}$ et al. Cancer Res 2010; 70: 9659-9670.

74. Tront JS et al. Cancer Res 2010; 70: 9671-9681.

75. Gurtner A et al. Cancer Res 2010; 70: 9711-9720.

76. Brignole $C$ et al. Cancer Res 2010; 70: 9816-9826.

77. Guo $Y$ et al. Cancer Res 2010; 70: 9875-9885.

78. Zhang $X$ et al. Cancer Res 2010; 70: 9895-9904.

79. Bonnaud $S$ et al. Cancer Res 2010; 70: 9905-9915.

80. Yanagisawa K et al. Cancer Res 2010; 70: 9949-9958.

81. Krishnamurthy S et al. Cancer Res 2010; 70: 9969-9978.

82. Wang L et al. Cancer Res 2010; 70: 10112-10120.

83. Okuyama H et al. Cancer Res 2010; 70: 10213-10223.

84. Colombo R et al. Cancer Res 2010; 70: 10255-10264.

85. Siddiqui-Jain A et al. Cancer Res 2010; 70: 10288-10298.

86. Lin JJ et al. Cancer Res 2010; 70: 10310-10320.

87. Woldemichael GM et al. Cancer Res 2011; 71: 134-142.

88. Bagci-Onder T et al. Cancer Res 2011; 71: 154-163.

89. Catena R et al. Cancer Res 2011; 71: 164-174.

90. Lopez $\mathrm{G}$ et al. Cancer Res 2011; 71: 185-196.

91. Li CM et al. Cancer Res 2011; 71: 216-224.

92. Jiang Y et al. Cancer Res 2011; 71: 234-244.

93. Indran IR et al. Cancer Res 2011; 71: 266-276.

94. Wang $Y$ et al. Cancer Res 2011; 71: 371-382.

95. Chang WH et al. Cancer Res 2011; 71: 383-392.

96. Iraci N et al. Cancer Res 2011; 71: 404-412.

97. Anderson VE et al. Cancer Res 2011; 71: 463-472.

98. Rérole AL et al. Cancer Res 2011; 71: 484-495.

99. Song JH et al. Cancer Res 2011; 71: 506-515.

100. Prasad S et al. Cancer Res 2011; 71: 538-549.

101. Smith BH. Cancer Res 2011; 71: 716-724.

102. Schiavoni $G$ et al. Cancer Res 2011; 71: 768-778.

103. Slupianek A et al. Cancer Res 2011; 71: 842-851.

104. Saydam $O$ et al. Cancer Res 2011; 71: 852-861.

105. Su CH et al. Cancer Res 2011; 71: 884-894.

106. Solier S, Pommier Y. Cancer Res 2011; 71: 906-913.

107. Brooke GN et al. Cancer Res 2011; 71: 914-924

108. Wang $X$ et al. Cancer Res 2011; 71: 925-936.

109. Papageorgis $P$ et al. Cancer Res 2011; 71: 998-1008.

110. Van Schaeybroeck S et al. Cancer Res 2011; 71: 1071-1080.

111. Mazumdar T et al. Cancer Res 2011; 71: 1092-1102.

112. Chang HY et al. Cancer Res 2011; 71: 1126-1134.

113. Nakazawa $Y$ et al. Cancer Res 2011; 71: 1146-1155.

114. Ji XD et al. Cancer Res 2011; 71: 1156-1166.

115. Sen T et al. Cancer Res 2011; 71: 1167-1176.

116. Hara K et al. Cancer Res 2011; 71: 1229-1234.

117. Aleksic T et al. Cancer Res 2010; 70: 6412-6419.

118. Xu T et al. Cancer Res 2010; 70: 6420-6426.

119. Yasui $\mathrm{H}$ et al. Cancer Res 2010; 70: 6427-6436.

120. Ladha J et al. Cancer Res 2010; 70: 6437-6447.

121. Wang $Y$ et al. Cancer Res 2010; 70: 6448-6455

122. Yang J et al. Cancer Res 2010; 70: 6456-6466.

123. Cao L et al. Cancer Res 2010; 70: 6497-6508.

124. Ratner $\mathrm{E}$ et al. Cancer Res 2010; 70: 6509-6515.

125. Moore LE et al Cancer Res 2010; 70: 6527-6536.

126. Coenegrachts $L$ et al. Cancer Res 2010; 70: 6537-6547.

127. Mao FJ et al. Cancer Res 2010; 70: 6548-6555.

128. lida $\mathrm{N}$ et al. Cancer Res 2010; 70: 6556-6565.

129. Kumar R et al. Cancer Res 2010; 70: 6649-6658.

130. Balaguer F et al. Cancer Res 2010; 70: 6609-6618.

131. Deka J et al. Cancer Res; 2010; 70: 6619-6628.

132. Metcalfe $C$ et al. Cancer Res 2010; 70: 6629-6638.

133. Ooi AT et al. Cancer Res 2010; 70: 6639-6648.

134. Kumar R et al. Cancer Res 2010; 70: 6598-6608.

135. Miki $Y$ et al. Cancer Res 2010; 70: 6659-6669.

136. Molina JR et al. Cancer Res 2010; 70: 6697-6703.

137. ladevaia $S$ et al. Cancer Res 2010; 70: 6704-6714

138. Shin SY et al. Cancer Res 2010; 70: 6715-6724.

139. Kerkar SP et al. Cancer Res 2010; 70: 6725-6734.

140. Gupta S et al. Cancer Res 2010; 70: 6735-6745.

141. Koike A et al. Cancer Res 2010; 70: 6746-6756.

142. Rimmelé $P$ et al. Cancer Res 2010; 70: 6757-6766.

143. Takakura $Y$ et al. Cancer Res 2010; 70: 6767-6778.

144. Toniolo $P$ et al. Cancer Res 2010; 70: 6779-6786.
145. Schöllnberger H et al. Cancer Res 2010; 70: 6797-6803.

146. Lingappa $\mathrm{M}$ et al. Cancer Res 2010; 70: 6815-6823.

147. Terzuoli E et al. Cancer Res 2010; 70: 6837-6848.

148. Hwang MK et al. Cancer Res 2010; 70: 6859-6869.

149. Gilbert CA et al. Cancer Res 2010; 70: 6870-6879.

150. Zhang YW et al. Cancer Res 2010; 70: 6880-6890.

151. Atkinson JM et al. Cancer Res 2010; 70: 6902-6912.

152. Muench $P$ et al. Cancer Res 2010; 70: 6913-6924.

153. Scarola M et al. Cancer Res 2010; 70: 6925-6933.

154. Salhia B et al. Cancer Res 2010; 70: 6934-6944.

155. Giannoni E et al. Cancer Res 2010; 70: 6945-6956.

156. House CD et al. Cancer Res 2010; 70: 6957-6967.

157. Si J et al. Cancer Res 2010; 70: 6968-6977.

158. Lagarrigue $\mathrm{F}$ et al. Cancer Res 2010; 70: 6978-6987.

159. Xu D et al. Cancer Res 2010; 70: 6988-6998.

160. Sloan EK et al. Cancer Res 2010; 70: 7042-7052.

161. Proulx ST et al. Cancer Res 2010; 70: 7053-7062.

162. Endo-Munoz L et al. Cancer Res 2010; 70: 7063-7072.

163. Allen-Petersen BL et al. Cell Death Dis 2010; 1: e17.

164. Bunk EC et al. Cell Death Dis 2010; 1: e15.

165. Cordeiro MF et al. Cell Death Dis 2010; 1: e3.

166. Hervouet E et al. Cell Death Dis 2010; 1: e8.

167. Ruela-de-Sousa RR et al. Cell Death Dis 2010; 1: e19.

168. Wirawan E et al. Cell Death Dis 2010; 1: e18.

169. Yacoubian TA et al. Cell Death Dis 2010; 1: e2.

170. Brandt B et al. Cell Death Dis 2010; 1: e23.

171. Ch'ng J-H et al. Cell Death Dis 2010; 1: e26.

172. McKeller MR et al. Cell Death Dis 2010; 1: e21.

173. Tomlinson V et al. Cell Death Dis 2010; 1: e29.

174. Pasupuleti N et al. Cell Death Dis 2010; 1: e31.

175. Deng L et al. Cell Death Dis 2010; 1: e32.

176. Giampietri $C$ et al. Cell Death Dis 2010; 1: e38.

177. Gorvel L et al. Cell Death Dis 2010; 1: e34.

178. Karaoz E et al. Cell Death Dis 2010; 1: e36.

179. Karlberg $M$ et al. Cell Death Dis 2010; 1: e43.

180. Lei W-W et al. Cell Death Dis 2010; 1: e44.

181. Meley D et al. Cell Death Dis 2010; 1: e41.

182. Paoletti R et al. Cell Death Dis 2010; 1: e45.

183. Placzek WJ et al. Cell Death Dis 2010; 1: e40.

184. Wang G, Bieberich E. Cell Death Dis 2010; 1: e46.

185. Flanagan L et al. Cell Death Dis 2010; 1: e49.

186. Chan K-S et al. Cell Death Dis 2010; 1: e57.

187. Fricker $M$ et al. Cell Death Dis 2010; 1: e59.

188. Knauer SK et al. Cell Death Dis 2010; 1: e51.

189. Li $Q$ et al. Cell Death Dis 2010; 1: e56.

190. Ben Mosbah I et al. Cell Death Dis 2010; 1: e52.

191. Ruiz A et al. Cell Death Dis 2010; 1: e54.

192. Sayeed A et al. Cell Death Dis 2010; 1: e53.

193. Tomiyama A et al. Cell Death Dis 2010; 1: e60.

194. Wabnitz GH et al. Cell Death Dis 2010; 1: e58.

195. Calandrella N et al. Cell Death Dis 2010; 1: e62.

196. Dribben WH et al. Cell Death Dis 2010; 1 : e63.

197. Gonzalez-Mejia ME et al. Cell Death Dis 2010; 1: e64.

198. Lam D et al. Cell Death Dis 2010; 1: e66.

199. Perrone L et al. Cell Death Dis 2010; 1: e65.

200. Upreti M et al. Cell Death Dis 2010; 1: e67.

201. El-Fadili AK et al. Cell Death Dis 2010; 1: e71.

202. Flourakis M et al. Cell Death Dis 2010; 1: e75.

203. Heidari $\mathrm{N}$ et al. Cell Death Dis 2010; 1: e76.

204. Janson V, Johansson A, Grankvist K. Cell Death Dis 2010; 1: e78.

205. Jiang CC et al. Cell Death Dis 2010; 1: e69.

206. Alajez NM et al. Cell Death Dis 2010; 1: e85.

207. Cheng JPX et al. Cell Death Dis 2010; 1: e82.

208. Marino ML et al. Cell Death Dis 2010; 1 : e87.

209. Matteucci C et al. Cell Death Dis 2010; 1 : e81.

210. Osato K et al. Cell Death Dis 2010; 1 : e84.

211. Reis CR et al. Cell Death Dis 2010; 1 : e83.

212. Schneider-Jakob S et al. Cell Death Dis 2010; 1: e86.

213. Tejedo JR et al. Cell Death Dis 2010; 1 : e80.

214. Bose R et al. Cell Death Dis 2010; 1: e92.

215. Karasawa T et al. Cell Death Dis 2010; 1: e102.

216. Lian J et al. Cell Death Dis 2010; 1: e94.

217. Sears D et al. Cell Death Dis 2010; 1: e93.

218. Sikkink LA, Ramirez-Alvarado M. Cell Death Dis 2010; 1: e98.

219. Sivananthan SN. Cell Death Dis 2010; 1: e100.

220. Wang Y et al. Cell Death Dis 2010; 1: e101.

221. Zhao C et al. Cell Death Dis 2010; 1: e95. 
222. Bhatnagar N et al. Cell Death Dis 2010; 1: e105. 223. Chu KME et al. Cell Death Dis 2010; 1: e106. 224. Gonzalez-Cano L et al. Cell Death Dis 2010; 1: e109. 225. Lee M-H et al. Cell Death Dis 2010; 1: e110. 226. McCoy F et al. Cell Death Dis 2010; 1: e108. 227. Benítez-Rangel E et al. Cell Death Dis 2011; 2: e113. 228. Degli Esposti D et al. Cell Death Dis 2011; 2: e111. 229. Ivanova $S$ et al. Cell Death Dis 2011; 2: e116. 230. Mahmoudi S et al. Cell Death Dis 2011; 2: e114. 231. Witte I et al. Cell Death Dis 2011; 2: e112. 232. Zhu Q-y et al. Cell Death Dis 2011; 2: e117. 233. Kumar A et al. Cell Death Dis 2011; 2: e119. 234. Kurata $\mathrm{M}$ et al. Cell Death Dis 2011; 2: e118. 235. Lembo-Fazio L et al. Cell Death Dis 2011; 2: e122. 236. Liu Y et al. Cell Death Dis 2011; 2: e121. 237. Guzik K et al. Cell Death Dis 2011; 2: e131. 238. Kelk P et al. Cell Death Dis 2011; 2. e126. 239. Krzyzowska M et al. Cell Death Dis 2011; 2: e132. 240. Lablanche $S$ et al. Cell Death Dis 2011; 2: e134. 241. Ling L-U et al. Cell Death Dis 2011; 2: e129. 242. Mühlethaler-Mottet A et al. Cell Death Dis 2011; 2: e125. 243. So EY et al. Cell Death Dis 2011; 2: e128. 244. Thellung S et al. Cell Death Dis 2011; 2: e138. 245. Miñano-Molina A et al. Cell Death Dis 2011; 2: e149. 246. Cheung HH et al. Cell Death Dis 2011; 2: e146. 247. Donadelli $\mathrm{M}$ et al. Cell Death Dis 2011; 2: e152. 248. Gao N et al. Cell Death Dis 2011; 2: e140. 249. Koster R et al. Cell Death Dis 2011; 2: e148. 250. Narducci MG et al. Cell Death Dis 2011; 2: e151. 251. Ahmed A et al. Cell Death Dis 2011; 2: e160. 252. Carmona-Gutiérrez D et al. Cell Death Dis 2011; 2: e161. 253. Liu H-L et al. Cell Death Dis 2011; 2: e159. 254. Mollinedo F et al. Cell Death Dis 2011; 2: e158. 255. Muglia C et al. Cell Death Dis 2011; 2: e163. 256. Quintavalle C et al. Cell Death Dis 2011; 2: e155. 257. Vaseva AV et al. Cell Death Dis 2011; 2: e156. 258. Zhang $Y$ et al. Cell Death Dis 2011; 2: e153. 259. Ahmed $Z$ et al. Cell Death Dis 2011; 2: e173. 260. Badmann A et al. Cell Death Dis 2011; 2: e171. 261. Barbone D et al. Cell Death Dis 2011; 2: e174. 262. Boehmerle W, Endres M. Cell Death Dis 2011; 2: e168. 263. Kuwahara Y et al. Cell Death Dis 2011; 2: e177. 264. Lim MP, Devi LA, Rozenfeld R. Cell Death Dis 2011; 2: e170. 265. Panzarini E, Inguscio V, Dini L. Cell Death Dis 2011; 2: e169. 266. Stevens JB et al. Cell Death Dis 2011; 2: e178. 267. Yivgi-Ohana N et al. Cell Death Dis 2011; 2: e166. 668. Kaur T et al. Cell Death Dis 2011; 2: e180. 269. Liu B et al. Cell Death Dis 2011; 2: e185. 270. Polier G et al. Cell Death Dis 2011; 2: e182. 271. Popov C et al. Cell Death Dis 2011; 2: e186. 272. Pujals A et al. Cell Death Dis 2011; 2: e184. 273. Zong D et al. Cell Death Dis 2011; 2: e181.
274. Coriat R et al. Cell Death Dis 2011; 2: e191. 275. Huelsenbeck J et al. Cell Death Dis 2011; 2: e190. 276. Lichtenberg M et al. Cell Death Dis 2011; 2: e196.

277. Osawa T, Davies D, Hartley JA. Cell Death Dis 2011; 2: e187. 278. Rauert $\mathrm{H}$ et al. Cell Death Dis 2011; 2: e194. 279. Thomas E et al. Cell Death Dis 2011; 2: e189. 280. Ai X et al. Cell Death Dis 2011; 2: e205. 281. Alameda JP et al. Cell Death Dis 2011; 2: e208. 282. Chauvier D et al. Cell Death Dis 2011; 2: e203. 283. Chi $\mathrm{S}$ et al. Cell Death Dis 2010; 1: e13. 284. Meltser V et al. Cell Death Dis 2010; 1: e20. 285. Morselli E et al. Cell Death Dis 2010; 1: e10. 286. Rodríguez J et al. J Cell Death Dis 2010; 1: e1. 287. Sassone J et al. Cell Death Dis 2010; 1: e7. 288. Silver N et al. Cell Death Dis 2010; 1: e14. 289. Straub WE et al. Cell Death Dis 2010; 1: e5 290. Yuan M et al. Cell Death Dis 2010; 1: e16. 291. Almasieh M et al. Cell Death Dis 2010; 1: e27. 292. Francis KR, Wei L. Cell Death Dis 2010; 1: e22. 293. Rello-Varona S et al. Cell Death Dis 2010; 1: e25. 294. Sancho-Pelluz J et al. Cell Death Dis 2010; 1: e24. 295. Tenedini E et al. Cell Death Dis 2010; 1: e28. 296. Manning JA, Kumar S. Cell Death Dis 2010; 1: e35. 297. Nicolai J et al. Cell Death Dis 2010; 1: e33. 298. Scheiman J et al. Cell Death Dis 2010; 1: e42. 299. Fujita E et al. Cell Death Dis 2010; 1: e47. 300. Mitchell GC et al. Cell Death Dis 2010; 1: e50. 301. Romano S et al. Cell Death Dis 2010; 1: e55. 302. Díaz-Manera J et al. Cell Death Dis 2010; 1: e61. 303. Schneider B et al. Cell Death Dis 2010; 1: e68. 304. Barton CE et al. Cell Death Dis 2010; 1: e74. 305. Bennett HL et al. Cell Death Dis 2010; 1: e72. 306. Wu PC et al. Cell Death Dis 2010; 1: e70. 307. Yelamanchili SV et al. Cell Death Dis 2010; 1: e77. 308. Rigaud $O$ et al. Cell Death Dis 2010; 1: e73. 309. Ciavardelli D et al. Cell Death Dis 2010; 1: e90. 310. Corona C et al. Cell Death Dis 2010; 1: e91. 311. Engel T et al. Cell Death Dis 2010; 1: e79. 312. Guardiola-Serrano F et al. Cell Death Dis 2010; 1: e88. 313. Tadokoro D et al. Cell Death Dis 2010; 1: e89. 314. Lanzillotta A et al. Cell Death Dis 2010; 1: e96. 315. Schmid R et al. Cell Death Dis 2010; 1: e97. 316. Jalmar $O$ et al. Cell Death Dis 2010; 1: e103. 317. Wemeau M et al. Cell Death Dis 2010; 1: e104.

Cell Death and Disease is an open-access journal published by Nature Publishing Group. This work is licensed under the Creative Commons Attribution-Noncommercial-No Derivative Works 3.0 Unported License. To view a copy of this license, visit http://creativecommons.org/licenses/by-nc-nd/3.0/ 